Fecha de recepción: 09-10-2017

Fecha de aceptación: 12-I-2018

Link para este artículo: http://dx.doi.org/10.14198/ALEUA.2018.29-30.12

Puede citar este artículo como:

Domingo, Javier, «Alfonso Sastre y José María de Quinto en las polémicas teatrales del medio siglo:

el discurso teatral de Correo literario (1950-1954)», Anales de Literatura Española, n. ${ }^{\circ} 29-30$ (2018),

pp. 245-263.

\title{
ALFONSO SASTRE Y JOSÉ MARÍA DE QUINTO EN LAS POLÉMICAS TEATRALES DEL MEDIO SIGLO: EL DISCURSO TEATRAL DE CORREO LITERARIO $(1950-1954)^{1}$
}

\author{
JAVIER DOMINGO \\ ITEM-UCM
}

\section{Resumen}

Correo literario (1950-1954) es una de las revistas del medio siglo de mayor interés: por la relación de escritores que colaboraron en ella, así como por la voluntad integradora que caracterizó su primera etapa bajo la dirección de Leopoldo Panero.

En este artículo nos proponemos el análisis, en concreto, de su discurso dramático. Se estudia, pues, su posicionamiento en las polémicas teatrales del medio siglo, en relación con el TEU y el papel que Sastre y de Quinto desempeñaron en ella como críticos. Los dos fundadores del TAS, ya conocidos teóricos teatrales y polemistas en una de las revistas del SEU, La Hora, utilizaron Correo literario como plataforma desde la que exponer sus ideas acerca de los temas de interés del momento: la proyección católica del teatro, su significación social y, como cuestión de fondo permanente, las diferentes posibilidades del realismo.

Palabras clave: Alfonso Sastre, José María de Quinto, Correo literario, Crítica teatral.

\begin{abstract}
Correo literario (1950-1954) is one of the most interesting periodic publication from the half of the XXth century: due to the value of its writers and the conciliatory disposition of his first editor, Leopoldo Panero.
\end{abstract}

1. La realización de este trabajo se inscribe dentro del marco de los contratos predoctorales para la Formación de Profesorado Universitario (FPU) que financia el Ministerio de Educación, Cultura y Deporte. Número de referencia: 2016/03916.

Anales, 29-30 (2018), pp. 245-263

DOI: 10.14198/ALEUA.2018.29-30.12 
Particularly, the current paper offers a lecture on Correo literario's dramatic discourse. It studies how this magazine take a stance on theatrical polemics from the half of the century, in relation to the activities of Teatro Español Universitario (TEU) and Alfonso Sastre and José María de Quinto as drama critics. Both authors, founders of TAS and well kown critics for La Hora, one of SEU's magazines, employed Correo literario to express their thoughts on the most controversial issues: the catholic implication of the theatre, its social significance and the different forms of Realism.

Keywords: Alfonso Sastre, José María de Quinto, Correo literario, Drama criticism.

\section{Introducción}

Correo literario es una de las tres revistas que proyectó y financió el Instituto de Cultura Hispánica (ICH) y que se editó con frecuencia quincenal, primero, y luego mensual, desde junio de 1950 hasta diciembre de 1954. Los 101 números que componen la revista se distribuyen en dos etapas y bajo dos direcciones diferentes: Leopoldo Panero desde el 1 de junio de 1950 (n. ${ }^{\circ} 1$ ) hasta el 1 de abril de 1952 (n. ${ }^{\circ} 45$ ); Juan Gich desde entonces hasta el último número de la segunda época, correspondiente a diciembre de 1954. Esta publicación reunió a las principales plumas de la literatura española del momento: poetas como Vicente Aleixandre, Blas de Otero o Claudio Rodríguez; dramaturgos como Antonio Buero Vallejo o Alfonso Sastre; narradores como Camilo José Cela o Carmen Laforet, por referirnos únicamente a creadores. Tal y como indica su subtitulo (Artes y letras hispanoamericanas), se caracterizó por una voluntad integradora entre las diferentes artes, así como por la vinculación de la vida intelectual española con la hispanoamericana y la europea. Aunque la publicación se ocupó principalmente de la producción artística peninsular (con atención incluso a la escrita en catalán), fueron numerosas las referencias a la literatura y el arte de países como Argentina, México, Francia o Alemania. La recuperación que llevó a cabo, en fin, de autores proscritos por la dictadura, así como de toda la literatura previa a la Guerra Civil, convirtieron a esta revista - en el periodo de dirección, sobre todo, de Leopoldo Panero- en una de las tentativas más sólidas de apertura cultural en lo que se ha denominado «la bisagra del Siglo de Plata español» (Cabañas Bravo, 2007).

En este trabajo, partiendo de una comprensión del producto hemerográfico no como fuente documental o repositorio de textos, sino como producto autónomo con un discurso significativo propio (Sobrino Vegas, 2014: 828), se estudiará el posicionamiento ideológico y cultural de la revista en las polémicas teatrales del medio siglo, en relación con el TEU y el papel que Sastre y de Quinto, compañeros de viaje en cuantos proyectos iniciaran durante la 
posguerra, desempañaron como críticos. Así pues, tras una necesaria introducción a la misma, se esbozará el lugar que en ella ocupan las representaciones y propósitos del TEU y los otros grupos de teatro de cámara y ensayo que conformaban la alternativa a la escena comercial. Para ello, nos centraremos de forma necesariamente sintética en tres momentos polémicos recogidos en Correo literario: el porvenir de un teatro católico en España, la cuestión del teatro social que desencadenaron los premios Pujol de 1951 y, finalmente, el debate en torno al realismo y la tragedia a propósito del estreno en España de La muerte de un viajante, de Arthur Miller.

\section{Correo literario (1950-1954), revista del Instituto de Cultura Hispánica}

El Instituto de Cultura Hispánica se fundó en 1946 y tuvo como primer director a Joaquín Ruiz Giménez, a la postre ministro de Educación Nacional durante el periodo de 1951 a $1956 .{ }^{2}$ La génesis del Instituto ha de buscarse en el Consejo de la Hispanidad, fundado en los cuarenta en el contexto de la II Guerra Mundial con un marcado carácter fascista. Durante el XIX Congreso Internacional del movimiento católico Pax Romana, celebrado en Salamanca y El Escorial durante el verano de 1946 y al que acudieron tanto Ruiz Giménez como Alfredo Sánchez Bella, segundo director del ICH desde 1948 hasta 1957, se vio la necesidad de una reformulación de las premisas que habían constituido el citado Consejo. En él se subrayó «el sentido tradicional del catolicismo hispánico que decía representar el régimen de Franco para hacerlo más aceptable ante el resto de congresistas procedentes de otros países europeos» (Cañellas, 2014: 78). En este sentido, el primer propósito del Instituto fue «insertar la política de relaciones culturales con Iberoamérica dentro del proceso de desfascitización de las instituciones españolas» (2014: 78). Fueron dos los puntales sobre los que cimentó su labor cultural: en primer lugar, la «reinterpretación de los ideales primitivos de Falange, a partir de una lectura de la herencia joseantoniana que asumía la unidad católica del pensamiento nacional, para reconocer la necesaria confesionalidad del Estado desde un prisma intelectual moderno que vivificara aquellas esencias» (2014: 81); en segundo lugar, un panamericanismo que buscaba tender lazos culturales con Hispanoamérica a fin de reforzar la imagen internacional del régimen, entre otras cuestiones de carácter económico y político.

2. Son varias las publicaciones dedicadas al análisis de la labor de la institución. Un extenso y documentado estudio sobre la misma es el preparado por María A. Escudero (1994), actualizado recientemente en un artículo por Cañellas Mas (2014); en concreto sobre las publicaciones del Instituto ha escrito González Casasnovas (2003). 
A este propósito, entonces, se destinaron los diferentes congresos y actividades de carácter cultural que se organizaron desde el Instituto, así como las numerosas publicaciones editadas bajo el sello de Cultura Hispánica, entre las que destacan, en el ámbito literario, la colección poética de La encina y el mar (donde vieron la luz poemarios fundamentales como La casa encendida de Rosales o Escrito a cada instante, del propio Panero) y las tres revistas de ediciones Mundo Hispánico: Correo literario (1950-1954), Cuadernos hispanoamericanos (1948-) y la homónima Mundo hispánico (1948-1957). Leopoldo Panero (1909-1962) se vinculó con el Instituto de Cultura Hispánica en los comienzos de los años cincuenta. Previamente, había trabajado como corrector de textos en el Instituto de Estudios Políticos de Madrid que dirigiera José María Castiella y había desempeñado el cargo de director del Instituto de España en Londres, donde tendió lazos con los exiliados (Cabañas Bravo, 2007: 91). Además, junto con Luis Rosales, Antonio de Zubiaurre y Agustín de Foxá, formó parte de la llamada embajada poética a América. ${ }^{3}$ Señala Cabañas Bravo que «acaso como compensación por haber asumido los riesgos de la citada misión poética iberoamericana, al igual que ocurrió con sus compañeros de viaje de diferentes formas, el Instituto de Cultura Hispánica nombró a Panero director de su nueva revista quincenal dedicada al arte y la literatura hispanos» (2007: 99); se le nombró Secretario General del I Congreso de Cooperación Intelectual y, posteriormente, también Secretario General de la Bienal Hispanoamericana de Arte (Cabañas Bravo, 2012). Pero es Correo literario la empresa de mayor interés literario de cuantas emprendiera en esos agitados y polémicos años cincuenta. Con ella, Panero «dio un ejemplo [...] de cómo entendía él la cultura. Basta dar el listado de colaboradores para darse cuenta de su talante liberal y generoso, reñido con cualquier sectarismo dogmático (Huerta Calvo, 2015: lxxiii). Aunque el autor de Escrito a cada instante solo dirigiera los 45 números - le seguiría en la dirección Juan Gich—fue aquel el que le imprimió su carácter, planteó sus diferentes secciones y su propósito y la constituyó, en definitiva, como una de las tentativas más sólidas de apertura cultural en lo que se ha denominado «la bisagra del Siglo de Plata español» (Cabañas Bravo, 2007), disintiendo de los parámetros ideológicos y culturales del ICH que se expusieron en la «Necesidad y propósito» de su número inicial. Este carácter

3. Sobre este polémico viaje, entre la política y la literatura, ha escrito Díaz: «que el objetivo del ministerio fuera [...] estrechar los lazos de amistad entre España y los países de habla española, rompiendo así el aislamiento internacional del régimen franquista, es un hecho y una medida diplomática consecuente con la situación, pero ninguno de los participantes en la "embajada" poética tuvo la propaganda política entre sus cometidos ni sus intenciones» (2012: 104). 
ambiguo de la revista se ha visto reflejado en las muy diferentes recepciones críticas de la publicación: así, mientras que para Fanny Rubio Correo literario «se va a mantener en unos derroteros trillados, defiende una poética y una literatura con anteojos» (2002: 102), José-Carlos Mainer, en una postura análoga a la de Javier Huerta, defiende su aproximación a un «clima de apertura y respeto intelectuales» (2013: 156).

\section{Teatro de cámara y ensayo: el TEU y el grupo de Arte Nuevo en las páginas de la revista}

Un buen ejemplo inicial del talante aperturista de la revista ya en el campo de lo teatral podría ser la inclusión de una reseña favorable, en su primer número, del que sería «el verdadero estreno en España de La casa de Bernarda Alba» (Quinto, 1986) a cargo del grupo de Teatro de Ensayo La Carátula y bajo la dirección de José Gordón y José María de Quinto. Este último ha proporcionado detalles sobre su desafortunado estreno $(1986,1999)$. Tras un laborioso esfuerzo por llevar la obra a las tablas (que conllevaba sortear tanto la censura como las condiciones que los herederos habían impuesto para las obras del granadino en la España del franquismo) se representó, en sesión única, el 20 de marzo de 1950. Pero su puesta en escena coincidió con un editorial de Ecclesia que prohibía la cobertura periodística de las representaciones de los grupos de cámara y ensayo. Tras la reacción internacional, desfavorable a esta restricción, «la Dirección General de Teatro tuvo que dar marcha atrás y pedir urgentemente a los periódicos que publicaran las críticas, las cuales se improvisaron de cualquier forma con tal de dar cumplimiento a la nueva orden» (1986: 26). ${ }^{4}$ Sorprende en este contexto, entonces, el texto que figura en la primera sección teatral de Correo literario ${ }^{5}$ : una crítica de la representación lorquiana a cargo de Jerónimo Toledano. En ella, tras una breve comparación de la honra en la obra y en los dramas calderonianos, se apunta la falta de atención crítica al drama lorquiano: «La crítica madrileña [...] prácticamente

4. Hubo, no obstante, algunas reseñas interesantes de mayor extensión, como la de Marqueríe en ABC (22-III-1950) o la de Sergio Nerva en España (22-IV-1950).

5. Conviene precisar en este punto que Correo literario no tiene sección teatral como tal. De manera discontinua incluirá contenidos dramáticos en sus páginas y abrirá secciones temporales (el caso de «Los Pujol, el premio Marshall de nuestras letras», dedicada a ese polémico certamen del que hablaremos más adelante). Desde el $n^{\circ} 81$, no obstante, hay una doble sección teatral fija en cada número: «Crónica de la quincena», de José María de Quinto, y «Cuaderno de notas», firmada por Alfonso Sastre. No se incluyeron en la revistas textos dramáticos, con la excepción de un texto breve de Carmen Conde en el $\mathrm{n}^{\circ} 5$, de corte existencial, así como otro de Luis Felipe Vivanco en el $\mathrm{n}^{\circ} 4$, aunque en este caso se trata más bien de una poética dialogada que de una obra teatral. 
ha prescindido de este estreno». Y lamenta, en general, la recepción del poeta en España: «Estamos seguros del estupor que habrá producido en cuantos siguen nuestro movimiento teatral, especialmente en Hispanoamérica, donde el valor innegable de Federico García Lorca, poeta, y el evidente de su teatro más logrado [...] tienen todo el calor y la alta valoración que también desde estas líneas proclamamos rotundamente» $(\mathrm{I}, 1,11){ }^{6}$

Las representaciones de los teatros nacionales — cuya labor se criticó duramente con asiduidad (una de las muestras más significativas es «Tempestad sobre los teatros nacionales» firmado por Sastre para el n. ${ }^{\circ}$ 56) — o los grandes autores comerciales tuvieron una amplia cobertura en la revista. Por ejemplo, la sección que desde el número 48 cerraba la revista y que consistía en una entrevista a un escritor de prestigio, se centró en muchas ocasiones en los populares autores de la comedia española de posguerra heredera de la comedia clásica española (Oliva, 2002: 151-152): Joaquín Calvo Sotelo (n. $\left.{ }^{\circ} 48\right)$, José María Pemán (n. ${ }^{\circ} 50$ ), José López Rubio (n. ${ }^{\circ} 61$ ) o Juan Ignacio Luca de Tena (n. ${ }^{\circ} 67$ ), entre otros. Pero el protagonismo fue sin duda para el teatro universitario y los grupos de cámara y ensayo.

Dentro de su planteamiento panamericanista la revista se refirió ampliamente a los teatros universitarios españoles, así como a los hispanoamericanos y de otras latitudes —en el n. ${ }^{\circ} 6$ se habla del teatro universitario de la UNAM, en el n. ${ }^{\circ} 61$ del Teatro Experimental de la Universidad de Chile o el n. ${ }^{\circ} 36$ del TEU de Coimbra-. Apenas aparecieron críticas de los espectáculos del TEU - los estrenos del TPU, desde su puesta de largo en 1953 con Escuadra hacia la muerte, recibirían notable atención ${ }^{7}$ - , pero sí valoraciones generales de la labor que estos desempeñaron en la renovación del panorama teatral español. En el número 81, Jaime Ferrán, tras exponer el creciente interés por lo dramático en los medios hemerográficos, elogia ampliamente el lugar del SEU en el panorama teatral actual: «Una de las cosas que más agradablemente me sorprendieron fue indudablemente la constatación de que el esfuerzo que mantuvo el SEU en el pasado curso (1952-1953), en lo que al teatro se refiere, ha sido seguido con unanimidad y con expectación por la inmensa mayoría de españoles que se preocupan por el teatro» (IV, 81, 3); en el n. ${ }^{\circ} 84$ se reclamaba

6. Las citas a artículos de Correo literario siguen siempre el siguiente criterio: (I —año-, 1 -número-, 1 -página-).

7. Además de algún artículo exclusivamente dedicado a la labor del TPU (IV, 86, 13), en el que se afirma con rotundidad: «Pocas veces en el teatro español, en esta historia últimamente tan despoblada de nuestro teatro, habíamos podido seguir paso a paso un empeño de tanta nobleza como el que nos ofrece el Teatro Popular Universitario del SEU», José María de Quinto, en su sección «Crónica de la quincena», repasará de manera sistemática las representaciones del grupo. 
la celebración de un congreso en Santander para tratar los problemas que achacaban al teatro en el cual se reservaba al TEU y al TPU un papel importante (IV, 84, 13); o, en el n. ${ }^{\circ} 62$, a propósito de la representación de Tres sombreros de copa en 1952 - a veces atribuida al TPU, pero en realidad última puesta en escena del TEU que dirigía Pérez Puig (García Ruiz, 2006: 105)—, se alababa la labor excepcional y destacable de dicho grupo en un contexto de «bajísima temperatura artística» caracterizado por la «languidez y el amaneramiento» (III, 62, 9).

La revista acoge, asimismo, dos artículos de José Gordón, germen de su futuro libro Teatro experimental español (1965). En ellos parte del teatro de comienzos de siglo y las andanzas de La Barraca hasta llegar a su presente inmediato. Del TEU en concreto destaca su propósito y dirección inicial —a cargo de Enrique Azcoaga y Modesto Higueras-, pero critica la deriva iniciada en 1948: «la programación fue cada vez más desacertada y descendió la calidad del cuadro de actores». El momento presente (1952), con Salvador Salazar como director, «promete ser una manifestación interesante» (III, 55, 8). Asimismo, dedica un amplio espacio a exponer la trayectoria del grupo Arte Nuevo, cuyos miembros, entre los que el propio Gordón se encuentra, tuvieron un especial protagonismo en las páginas dramáticas de Correo literario.

En efecto, colaboraron en la revista Alfonso Paso, Medardo Fraile o José Gordón y, sobre todo, José María de Quinto, con veintiún artículos, y Alfonso Sastre, con cuarenta y uno. ${ }^{8}$ Anteriormente, los fundadores del Teatro de Agitación Social (TAS) habían desempeñado una intensa labor crítica en La Hora, una de las revista dependientes del SEU. ${ }^{9}$ En ella comienza la andadura de Sastre como espectador crítico de «un teatro estancado y fraudulento» (Caudet, 1984: 111), que denuncia la inoperancia de los teatros nacionales y que va perfilando su postura desde una primera actitud estética experimental hacia el manifiesto del TAS, publicado en ese mismo medio en septiembre de $1950 .{ }^{10}$ Tras la clausura de la revista, Alfonso Sastre y su compañero de Quinto pasaron

8. En el «Anexo I» incluimos una relación de los artículos de José María de Quinto y Alfonso Sastre publicados en la revista.

9. Francisco Caudet (1984) ha estudiado la labor de Alfonso Sastre como crítico en las páginas de La Hora. Manuel Aznar Soler (1993), por su parte, ha hecho un repaso sistemático por toda la trayectoria de José María de Quinto como teórico y crítico. Ambos coinciden en el importante espacio que ocupa Correo literario en su recorrido como ensayistas.

10. En el artículo «El TAS por última vez», publicado en el 1 de octubre de 1950 en La Hora, Alfonso Sastre denomina a esta serie de artículos la campaña 1949-1950: «Como antecedente del Manifiesto del TAS tengo que citar mi campaña, íntegramente desarrollada en La Hora, en el curso 1949-1950, en torno a un teatro de agitación como posibilidad purificadora y revolucionaria». En ese mismo lugar, Sastre da una relación completa de los artículos de la campaña. 
a escribir con asiduidad en muchas otras publicaciones, y en especial en dos de las revistas del Instituto de Cultura Hispánica, Cuadernos hispanoamericanos y, sobre todo, Correo literario, como se ha señalado en repetidas ocasiones (Caudet, 1984: 126; Aznar Soler, 1993: 210; García Ruiz, 2006: 119-120). Fue quizás su carácter oficial, al igual que ocurría en La Hora, así como la mano directora de Leopoldo Panero, lo que conllevó paradójicamente una amplitud de expresión mayor que en otros medios. Hasta el periodo último de la revista intervienen de forma intermitente en cuantas polémicas se produjeron en la revista (y a ello atenderemos en las páginas siguientes). Pero no será hasta el número 81 cuando ambos adquieran sección propia. De Quinto firmará la "Crónica de la quincena», un repaso sistemático de la temporada teatral en que critica con frecuencia la programación de los teatros comerciales y defiende los ímprobos esfuerzos de los jóvenes, y Sastre «Cuaderno de notas», espacio teórico que dedicó a los más variados aspectos del hecho teatral y que sería la base de su posterior Drama y sociedad (1956).

\section{Lo católico y lo social}

En referencia al momento literario del cambio de década, García Ruiz destacaba la pasión con que «se producían discusiones y polémicas por asuntos de teatro» en las revistas literarias de la época, y cómo «dentro siempre de unos límites Alfonso Sastre, José María de Quinto o Buero Vallejo encontraron plataformas desde las que exponer con alguna holgura sus puntos de vista» (2006: 12). Correo literario, que cultivó ampliamente la encuesta y el artículo de opinión sobre temas polémicos, no fue una excepción y se hizo eco, pues, de un clima de debate en que lo católico y lo social en el teatro eran cuestiones de permanente cuestionamiento (2006: 12).

El n. ${ }^{\circ} 23$ fue el origen de una prolongada polémica en torno al teatro católico (II, 23, 6-7). ${ }^{11}$ Anteriormente ya se había mostrado el interés por la búsqueda de una dramaturgia en esta línea de pensamiento: en el número 5, por ejemplo, que reseñaba la representación de un auto sacramental por un teatro universitario de la UNAM. Este grupo, «un confortable ejemplo de armonía nacional cristiana», entra en pugna con otros «grupos experimentales de teatro que tratan de hacer triunfar ideas no católicas, como, por ejemplo, las ideas del teatro de Sartre» (I, 5, 9). En dicha encuesta se afirmaba el propósito de encauzar el teatro «por uno de los caminos más fértiles del pensamiento y la

11. García Ruiz señala que «la preocupación por el arte y la literatura católicas es un fenómeno general en la Europa continental, vinculado a la experiencia de la Guerra Mundial y aún más a la de la posguerra» (2016: 152). 
acción contemporáneos: por el camino de la catolicidad». Se preguntaba a diez hombres de teatro sobre las siguientes cuestiones: 1) ¿Qué bases redactaría Vd. para un gran concurso de teatro católico de franco estilo, tema y tono actuales?; 2) ¿Qué cuantía mínima debería fijarse para premiar la obra elegida? En las respuestas prevalece sin duda la postura de que un teatro católico no debe ser necesariamente un teatro de tema católico: «Cualquier tema - y cuanto más zarandeado por el oleaje, mucho mejor, puede y debe recibir un enfoque católico» (Enrique Llovet); e incluso se relacionaba con el verdadero teatro social: «un tema social o de conciencia de carácter universal resuelto de acuerdo con las normas de la iglesia» (Jorge de la Cueva). Y debe ser, ante todo, formalmente aceptable: «teatro bueno como tal teatro, en todos los órdenes, porque eso es lo más teatralmente católico que hay» (González Ruiz). Gonzalo Ballester es el más sistemático en su respuesta:

En tres grupos creo que debe dividirse el teatro católico. [...] Uno, aquel en que los personajes y sus conflictos viven y se desarrollan dentro de una concepción católica del mundo. [...] Otro en que el tema o el conflicto son de índole religiosa. [...] Finalmente, un tercero, en que lo que se pretende no es la creación de una obra dramática, sino la exposición o demostración de una tesis de contenido católico. ${ }^{12}$

En el número siguiente, Alfonso Sastre respondía con una «contestación espontánea a una encuesta sobre teatro católico» en la que manifiesta su desacuerdo con la idea del hipotético concurso y señala la incongruencia de rechazar, como en efecto hace una mayoría de los encuestados, el teatro de propaganda católica, que es como entiende Sastre cualquier teatro católico: «ipor qué eliminar [...] el teatro verdaderamente católico, el teatro de propaganda católico: el único teatro que puede llamarse de verdad católico?». Sin por ello defender, claro, dada su postura social-realista, un teatro de pureza estética: «creo que el dramaturgo debe enrolarse en una determinada forma ideológica de vida, aun a costa de la pureza objetiva de su testimonio y de la pureza artística de su trabajo (II, 24, 2).

De menor interés son las respuestas que, más de diez números después, la Tertulia Teatral de Zaragoza ofrecía sobre las cuestiones preguntadas. Allí defienden «un teatro viril, polémico, que combata con energía a todos los grandes pecados de la civilización actual» (Pedro Galán Bergua), de «sencillez

12. Del mismo modo, en el número 44 Gonzalo Torrente Ballester exploraba la condición cristiana y católica de Cocktail Party, drama de T. S. Eliot, concluyendo que su fracaso era consecuencia de abordar el problema del adulterio desde una perspectiva cristiana, y solo vagamente católica: «A nosotros, sin embargo, este cristianismo se nos escapa. Nos parece demasiado vago, abstracto» (III, 44, 12). 
evangélica» en el estilo, que no necesitaría más ayuda «que la de Dios para una buena voluntad de creyente» (José María Salvador) y que combata el «teatro amargo, escéptico, con fuerte sabor ateo en su fondo y tintes de traducción americana» (Dámaso Santos y J. Giménez Aznar).

En todas estas discusiones ideológicas está latente la cuestión de lo social en el arte, tema de candente actualidad en todos los géneros y formas artísticas de la época. Al frente del Manifiesto TAS Sastre y de Quinto habían afirmado, no sin cierto afán de provocación, que «lo social, en nuestro tiempo, es una categoría superior a lo artístico» (La Hora, n. ${ }^{\circ}$ 63). Sobre esta premisa Sastre prepara, en el número 30, una encuesta en torno al teatro social. Introduce la misma un extenso prólogo en el que, tras referir el éxito que el manifiesto TAS tuvo el año pasado entre la juventud, defiende que el teatro es social por su proyección masiva y porque el dramaturgo ha de «recoger la angustia social de esta hora y denunciarla». Contrasta el autor de Escuadra hacia la muerte su opinión sobre el momento dramático con la postura de los dramaturgos: «Pero los autores españoles de hoy se manifiestan, de modo unánime, en desacuerdo con estas ideas». Los encuestados, en efecto, expresaron su oposición: Calvo Sotelo, López Rubio (con un rotundo «no» como respuesta), Pemán, quien expuso una elaborada respuesta en referencia a la anterior polémica sobre teatro católico, y Buero Vallejo, afirmando que todo verdadero teatro «es por esencia el arte representativo de las sociedades humanas» (II, 30, 5).

Leocadio Machado, en el número siguiente, también se haría eco de la encuesta y le respondería a Sastre con ironía afirmando que « $¡$ Ya tenemos teatro social! ». Se refería a los polémicos premios Pujol, dotados con la generosa suma de 100.000 pesetas. ${ }^{13}$ Alfonso Sastre le responde en «Pocas palabras sobre el concurso Pujol», inscrita en una sección de título «Los Pujol, plan Marshall de nuestras letras». Allí critica la misma concepción del concurso y sobre todo la falsa noción de lo social que propagaba — y que motivó la respuesta airada de Machado-: «Ya el hecho de proponer una tesis es detestable. Pero es que, además, las tesis propuestas eran superficiales y, en definitiva, falsas» (II, 32, 12). En la misma página, José María de Quinto se refería a que el concurso, «al exigir una tesis, se convertía, desde su nacimiento, en el concurso más antiteatral e ineficaz de todos cuantos se han convocado hasta la fecha», de ahí

13. Como afirma García Ruiz, «se les criticaba su inutilidad ya que podía concurrir cualquier escritor, consagrado o no, que, además, debía ceñirse a unos temas de tipo social o ideológico que se les marcaban como condición» (2006: 21-22). Los premiados fueron, entonces, autores consagrados con obras forzadas para su adecuación a las condiciones del concurso. 
el título del artículo: «La tesis es la tisis del drama» (II, 32, 12). Desde unos presupuestos muy diferentes Emilio Romero cargaba contra cierta idea de teatro social, político, vinculado con el socialismo: «Este teatro social de detrás del socialismo podría tener su ocasión [...] Pero corrientemente se transforma en teatro político, en mera peripecia o aventura, que en nuestro país alcanza sus tonos más inconvenientes». Para acabar defendiendo una noción de lo social totalmente vaga e imprecisa: «El teatro social, ¿no será exclusivamente aquel que nos diga lo que sucede en las almas, y no lo que pasa en la vía pública?» (II-34/35-7).

Pero al margen de cualquier polémica, los firmantes del manifiesto por un Teatro de Agitación Social reflexionaron reiteradamente sobre este aspecto. De Quinto, además de las consideraciones aisladas en su sección fija «Crónica de la quincena», desarrolla sus ideas sobre lo social en un artículo publicado en el número 61 bajo el título de «Lo intimista en la literatura social» (III, 61, 3). Se centra en las relaciones entre literatura social y propaganda, y afirma que las teorías teatrales de Piscator han perjudicado el devenir de este tipo de dramaturgia en cuanto que reducían las obras a dramas de tesis. El escritor afirma que «esta nueva edad literaria», caracterizada por el realismo y el interés en lo social, se manifiesta en aquellos dramas que conjugan lo social con lo individual o intimista (Toller, Upton, Sinclair o Miller son algunos de los ejemplos que ofrece).

Del mismo modo, Alfonso Sastre desarrolla en las páginas de Correo literario una elaborada teoría dramática que luego formará parte de Drama y sociedad (1956) y en menor medida de Anatomía del realismo (1965). Además de los artículos referidos a la polémica de los Pujol, es especialmente interesante el titulado «Sobre las formas sociales del drama», respuesta a otro de García Luengo, publicado en Índice a raíz, precisamente, de la encuesta firmada por Sastre en Correo de la que hemos hablado más arriba. Las conclusiones son fundamentalmente las de su libro de 1956: según Sastre, el teatro social se caracteriza $« 1^{\circ}$. Por su proyección (sobre extensas zonas de espectadores). $2^{\circ}$. Por su tema (temas en que están interesados grandes grupos humanos en cuanto grupos). $3^{\circ}$. Por su intención (el dramaturgo intenta, deliberadamente, una repercusión social purificadora)» (III, 39, 14; Sastre, 1956: 69-72). Finalmente, hay que subrayar la insistencia con que Sastre incide en la calidad dramática de la obra: «El teatro político es artísticamente válido -y solo al serlo artísticamente lo es socialmente- cuando la consecuencia política es un último resultado que arroja, sin esfuerzo, la trama, la fábula, el mito» (1956: 119), que lo alejaría del teatro de propaganda que de Quinto y Sastre atribuyen con matices a Piscator en el campo de la teoría (Quinto: III, 
61, 3; Sastre, 1956: 111). En 1976, de hecho, Sastre se refiere a sus ideas de entonces: «Yo suscribía ya [la tesis de que todo arte es propaganda], matizadamente, en aquellas fechas, a pesar de los repeluznos que me producía la tesis piscatoriana, para mí inaccesible por entonces, de "un arte de partido" » (1976: xii).

\section{Tragedia y realismo en el teatro de los años cincuenta}

La cuestión de fondo que rige lo anteriormente referido - y me atrevería a decir, todas las polémicas sobre estética de Correo literario- es el debate en torno al realismo. Lo referencial del arte, su relación con la política o sus diferentes grados de autonomía fueron los temas principales de discusión en todas las artes durante la posguerra, desde la poesía hasta la pintura, tal y como estudia Sultana Wahnón en La estética literaria de la posguerra (1998). Aunque por tiempo y espacio no podemos delinear con precisión la postura de Correo literario, respecto de este problema podemos concluir que si bien predominaba la predilección por el arte y la literatura figurativos - y en esta categoría podemos incluir lo católico y lo social en cuanto estéticas contrarias al esteticismo y el purismo que diagnosticara Ortega y Gasset en La deshumanización del arte (1925) — estuvo abierta a concepciones de carácter antimimético: por ejemplo, la poesía de Jorge Guillén o la pintura abstracta, que tanta importancia tendrían en las Bienales Hispanoamericanas de Arte y en las reuniones de la Escuela Altamira, ampliamente reseñadas en Correo ${ }^{14}$ Pero ello no fue obstáculo para que la revista incluyera voces disidentes. Alfonso Sastre, precisamente, afirma que «no cree [...] en el porvenir del arte geometrizante, afigurativo». Y niega la concepción del escritor como creador de belleza: «para mí la belleza es algo secundario» (IV, 79,9), aspecto este en el que insistirá en un artículo que luego se incluirá íntegramente en Drama y sociedad, «Otra vez la belleza», en el que precisa aún más la situación del teatro respecto de esta cuestión estética:

Porque resulta que todo lo dicho está meditado por mí de un modo especial sobre un fenómeno artístico concreto: el Teatro. Anoto, para terminar, que el Teatro no ha llegado nunca, a pesar de los esfuerzos de muchos "invasores", a la desintegración, a la deshumanización —hablo de deshumanización a la vista de numerosos casos de mutilación de la realidad humana que se han

14. No se nos escapa que esta vinculación con un arte más formalista está relacionada con el denominado pacto con la deshumanización estética, que consistió en el acercamiento a formas de arte relacionadas con los preceptos orteguianos de la deshumanización por parte de autores e instituciones que anteriormente habían apostado por estéticas de carácter referencial como una forma de oposición al renovado empuje de la poesía social en los años 50 (Wahnón, 1998). 
dado en el arte contemporáneo- a que, en la entreguerra, llegaron la Poesía y la Pintura (IV, 81, 10).

José María de Quinto también advertía del riesgo de deshumanización que corría el teatro e identificaba este concepto con la evasión: «Todo parece dispuesto para entrar en un periodo de franca "evasión". En la "profundización" — granazón del realismo- se siente el pálpito del testimonio documental de la época [...] Mientras que en la "evasión" los problemas testimoniales son absorbidos por una fábula en la que puede participar lo sobrenatural, se alejan y deshumanizan» (III, 55, 1).

En el caso concreto del teatro, además, el realismo es sinónimo de género trágico. En este sentido, Buero Vallejo, en un emotivo comentario sobre su Historia de una escalera, exponía su propósito: «yo había intentado, bajo la superficie sainetesca y costumbrista de mi obra, deslizar una tragedia auténtica» e insistía en el carácter amargo de su obra, de ahí el título del artículo, como una advertencia: «Cuidado con la amargura». Reclamaba, en fin, la catarsis como finalidad de la obra teatral y denunciaba la proliferación de comedias y revistas frívolas que solo buscaban la risa fácil. También en una entrevista a Joaquín Calvo Sotelo realizada por Sastre se insistía en la falta de dramaturgos trágicos en la escena: «Nuestro teatro actual está servido más por comediógrafos que por dramaturgos. Me parece percibir un deseo latente, en los espectadores y en los autores, de enfrentarse con los grandes temas de nuestros días» (III, 40, 12).

Es muy conocido el artículo «Teatro de magia y teatro de angustia» en el que Sastre apuesta, como Buero, por la amargura:

La otra corriente, la que hemos llamado "teatro de Angustia", es el resultado de una conciencia distinta en torno al teatro, su sentido y su función. Es la corriente propiamente trágica del teatro moderno, sustentada en los postulados del realismo. Es el teatro que recoge la existencia como un tremendo desgarrarse temporal, sin magias ni fantásticas evasiones. Es el teatro en el que resuenan las cosas como son. Esta es la corriente provocada por los grandes dramaturgos testigos (III, 55, 8).

La reflexión que lleva a cabo sobre el género es notable, y se manifiesta en múltiples artículos teóricos que luego aparecerán en forma de libro: «Eugenio O'Neill en la resurrección de la tragedia» (IV, 86, 12), «Tragedia antigua y tragedia moderna» (IV, 86, 10), «La "katharsis" trágica» (V, 90, 10) o «La tragedia y el tiempo» $(\mathrm{V}, 92,10)$, por citar algunos de los de su última etapa en la revista. 
También de Quinto reclamaba una mayor presencia del género trágico en las tablas españolas: ${ }^{15}$

Si se piensa en las obras representadas en estos últimos días, nos sentiremos suavemente mecidos por toda una marejada de "teatro amable", blando, tranquilizador, un teatro que enmascara la realidad política y social de nuestro tiempo y trata, por medio de la falsa y confiada alegría, de adormecer las conciencias [...] Señalamos, desde aquí, la ausencia del drama y de la tragedia, el inminente peligro de que su aliento purificador y necesario no sople, en este año teatral, por nuestros escenarios. En este sentido, cabe añadir que en tanto la tragedia no haga su aparición no podremos hablar seriamente de teatro nacional (IV, 82, 10).

Por supuesto, Sastre tuvo detractores de sus ideas en Correo. Charles David Ley, por ejemplo, a propósito de las discutidas tragedias contemporáneas, refería que «presentan escenas muy dolorosas de la vida contemporánea en diversas partes. Pero, desde el punto de vista de la tragedia, los problemas que presentan me parecen demasiado parciales y locales» (IV, 80, 10). Precisamente, una de las obras que cita como ejemplo es La muerte de un viajante de Arthur Miller, ${ }^{16}$ la cual ya había provocado cierta polémica en la revista, y sobre la que Sastre reflexionará largamente en sus libros teóricos. Los protagonistas de la disputa, iniciada en el diario Arriba, son los habituales Torrente Ballester y Sastre, y en ella se recogen los principales preceptos teóricos de que venimos hablando. El crítico gallego dice de la obra que es una pieza naturalista de tesis y la califica de alegato, en cuanto que como fotografía realista selecciona aquella parte de la realidad, en este caso los aspectos más desagradables, para demostrar, falsamente, una tesis concreta. Por último, critica la concepción social del arte, aunque siempre dentro de un mismo paradigma realista («el arte, según mi anticuado entendimiento, sirve a cosas más altas, referidas, precisamente, al hombre»), según la cual el drama «muestra, denuncia, hace patente algo» (III, 43, 12).

En esa misma página figuraba la respuesta de Sastre. En ella, defiende en primer lugar la actualidad y vigencia del teatro documento —además de Miller, menciona a Saroyan o Steinbeck, entre otros-y su validez como fundamento de una tragedia: el autor parte «del documento existencial, es decir, del comportamiento real del hombre en lugar y momento determinados. Penetra esta forma en el hombre, a través de su existencia, según diversos grados de

15. En 1962, José María de Quinto publicaría La tragedia y el hombre (Notas estético-sociológicas) en el que, desde una perspectiva mucho más teórica, reivindica la necesidad de una tragedia moderna.

16. La obra se estrenó el 10 de enero de 1952 en el teatro de la Comedia de Madrid, en versión de José López Rubio y bajo la dirección de José Tamayo. 
profundización que pueden llegar al hallazgo esencial, a la emoción universal humana, ontológica» (III, 43, 12). En otro lugar, Sastre reflexiona también sobre cómo afecta la cuestión social (el hecho de que una reforma del sistema de trabajo resolvería la situación del protagonista) a su condición genérica, concluyendo que esto no afecta a su sustancia trágica, puesto que aunque haya una posibilidad de salir de su situación, Loman no la ve y no puede hacer nada por cambiar sus condiciones (1956: 36). También de Quinto se haría eco de esta polémica en su artículo «Europa, América y sus dos teatros». En él, tras rebatir el supuesto carácter naturalista de la obra de Miller, defiende la vigencia realista del teatro norteamericano, caracterizado por dos aspectos esenciales: «De un lado el signo social, y de otro, el meramente humano, ambos estrechamente ligados entre sí. [...] Antes, el héroe trágico tenía necesariamente que estar representado por un rey, por una alta dignidad humana. Hoy, por el contrario - debemos comprenderlo de una vez- el héroe trágico es un William Loman cualquiera, un hombre gris, indeterminado, componente de la masa» (III, 54, 8).

En cualquier caso, la discusión en torno a Miller hace patente el interés permanente de los redactores de Correo - y del sistema literario español de la década de los cincuenta en general — por la ética y estética del realismo. ${ }^{17}$

\section{Conclusiones}

Como afirma Cabañas Bravo, la revista literaria «es un lugar ideal para la observación de los enfrentamientos y del despliegue de estrategias de diversos grupos productores de cultura, creando espacios discursivos mediadores, imprescindibles para el discernimiento de los mecanismos de consolidación de la hegemonía cultural» (2002: web). García Ruiz se refería, en concreto, a la polémica como elemento definidor de las revistas del medio siglo, uno de los momentos literarios recientes de mayor interés en cuanto bisagra del Siglo de Plata de nuestras letras, a medio caballo entre los años cuarenta, de autarquía cultural y reestructuración del campo literario, y los años sesenta, de apertura e internacionalización (Cabañas Bravo, 2007: 29).

Correo literario en concreto, una de las tres revistas que editó el Instituto de Cultura de Hispánica — queda para otro momento el análisis dramático de las dos restantes: Cuadernos Hispanoamericanos y Mundo hispánico-, es

17. Las razones éticas del realismo es el título de un libro de José Jurado Morales (2014) sobre Revista Española, publicación fundada por Antonio Rodríguez Moñino y que durante los seis números que se publicaron entre 1953 y 1954 defendió el realismo como posición estética. Alfonso Sastre, precisamente, fue uno de sus redactores. 
especialmente interesante por su voluntad integradora y de apertura, resultado, en última instancia, del buen hacer de Leopoldo Panero, quien dirigió y marcó el camino a seguir durante la primera etapa de la misma. Del análisis de los textos referidos al teatro que en ella aparecen, se puede concluir que aunque los grandes teatros y autores comerciales —al margen del fenómeno del torradismo (Oliva, 2002: 149) — tuvieron una amplia representación en la revista (en forma, sobre todo, de reseñas y entrevistas personales), prevaleció, sin duda, el interés por propuestas del circuito alternativo, como diversas compañías de teatro de cámara y ensayo, diferentes TEU españoles y extranjeros y, principalmente, el grupo Arte Nuevo y TAS. José María de Quinto y sobre todo Alfonso Sastre, ya conocidos teóricos teatrales y polemistas en una de las revistas del SEU, La Hora, utilizaron Correo literario como plataforma desde la que exponer sus ideas acerca de los temas de interés del momento: la proyección católica del teatro, su significación social y, como cuestión de fondo permanente en la revista, las diferentes formas del realismo.

\section{Bibliografía citada}

Aznar Soler, M., «José María de Quinto, crítico teatral del realismo social», Cuadernos Interdisciplinarios de Estudios Literarios, IV, 1 (1993), pp. 207-232.

CABAÑAS, T., «La revista literaria: campo de tensiones y estrategias culturales», Proceedings of the 2. Congreso Brasileño de Hispanistas (2002); <http://www. proceedings.scielo.br/scielo.php?script=sci_arttext\&pid=MSC00000000120 02000300062\&lng=en\&nrm=iso > [consulta: 07-XI-2017].

CABAÑas Bravo, M., Exilio e interior en la bisagra del Siglo de Plata español. El poeta Leopoldo Panero y el pintor Vela Zanetti en el marco artístico de los años cincuenta, Astorga, Ayuntamiento de Astorga, 2007.

—, «Leopoldo Panero y las bienales hispanoamericanas de arte», Astorica, 31 (2012), pp. 183-208.

CAÑEllas MAS, A., «Las políticas del Instituto de Cultura Hispánica, 1947-1953», Historia Actual Online, 33 Invierno (2014), pp. 77-91.

CAUDET, F., «La Hora (1948-1950) y la renovación del teatro español de posguerra», en J. M. López de Abiada (ed.), Entre la cruz y la espada, en torno a la España de posguerra: homenaje a Eugenio G. de Nora, Madrid, Gredos, 1984, pp. 109-126. DíAZ DE Alda HeikKila, M., «Aventuras y desventuras de Panero en la misión por América», Astorica, 31 (2012), pp. 99-130.

EsCudero, M. A., El Instituto de Cultura Hispánica, Madrid, Editorial Mapfre, 1994. García Ruiz, V., «El teatro español entre 1950 y 1955», en V. García Ruiz \& G. Torres Nebrera (eds.), Historia y antología del teatro español de posguerra. Vol. III. 1951-1955, Madrid, Fundamentos, 2006, pp. 11-172. 
GONZÁlez CaSAnOvas, I. (ed.), La huella editorial del Instituto de Cultura Hispánica: Ediciones Cultura Hispánica y otras publicaciones: estudios y catálogo (19441980), Madrid, Fundación Mapfre Tavera: Ministerio de Asuntos Exteriores, 2003.

GORDON, J., Teatro experimental español: (antología e historia), Madrid, Escelicer, 1965.

Huerta Calvo, J. (ed.), Gerardo Diego y la Escuela de Astorga, Astorga, Fundación Gerardo Diego \& Centro de Estudios Astorganos Marcelo Macías, 2016.

JURAdo MORALES, J., Las razones éticas del realismo: Revista Española (1953-1954) en la literatura del medio siglo, Sevilla, Renacimiento, 2012.

MAiner, J. C., Falange y literatura, Barcelona, RBA libros, 2013.

Monleón, J., Treinta años de teatro de la derecha, Barcelona, Tusquets, 1971.

Oliva, C., Teatro español del siglo XX, Madrid, Síntesis, 2002.

QUINTO, J. M., La tragedia y el hombre (Notas estético-sociológicas), Barcelona, Seix Barral, 1962.

- «Sobre el verdadero estreno en España de La casa de Bernarda Alba», Ínsula, 476-477 (1986), pp. 8, 26.

—, «Memoria personal sobre el teatro», en L. García Lorenzo, Aproximación al teatro español universitario (TEU), Madrid, Instituto de la Lengua Española, 1999, pp. 63-110.

Rubio, F., Las revistas poéticas españolas, 1939-1975, Alicante, Publicaciones de la Universidad de Alicante, 2003.

SASTRE, A., Drama y sociedad, Madrid, Taurus, 1956.

—, [1965] Anatomía del realismo, Barcelona, Seix Barral, 1974.

—, Prólogo a E. Piscator, Teatro político, Madrid, Ayuso, 1976, pp. vii-xxi.

SOBRINO VeGAS, A. L., Las revistas literarias en la II República, Tesis doctoral inédita, Universidad Nacional de Educación a Distancia, 2012.

WAHNÓN, S., La estética literaria de la posguerra: del fascismo a las vanguardias, Ámsterdam, Rodopi, 1998.

\section{Anexo I}

\section{Artículos de Alfonso Sastre y José María de Quinto en Correo literario}

\section{Alfonso Sastre}

«El teatro, en estado de alarma», II, 17, p. 4.

«Nota sobre Lenormand», II, 21, p. 8.

«Contestación espontánea a una encuesta sobre teatro católico, II, 24, p. 2.

«Hablamos con Jardiel Poncela», II, 28, p. 1.

«Los autores españoles ante el teatro como "arte social”», II, 30, p. 5.

«Pocas palabras sobre el concurso Pujol», II, 32, p. 12. 
«Los "grandes" del teatro español hablan del teatro mundial», II, 34-35, p. 7. «El autor no es más que la tercera parte del teatro», II, 37-38, pp. 7, 10.

«Sobre las formas «sociales» del drama», III, 39, p. 14.

«Joaquín Calvo Sotelo: premio Benavente», III, 40, p. 12.

«Suárez Carreño: premio Lope de Vega», III, 40, p. 12.

«Loman es un hombre dolorosamente vivo», III, 43, p. 12.

«Mutis definitivo de Enrique Jardiel Poncela», III, 44, p. 12.

«La crítica teatral no funciona», III, 46, p. 10.

«Un estreno en ocho notas», III, 47, p. 11.

«El teatro desde el cero al infinito», III, 50, p. 7.

«Teatro de magia y teatro de angustia», III, 54, p. 8.

«Tempestad sobre los teatros nacionales», III, 56, pp. 1, 10.

«El teatro en el libro», III, 56, p. 8.

«Tragedia», IV, 70, p. 10.

«Nueva salida del Teatro Popular Universitario», IV, 72, p. 10.

«Ugo Betti», IV, 75, p. 10.

«Nuevos empresarios para la escena española», IV, 76, p. 14.

«El drama y las ideas», IV, 77 , p. 10.

«Ante la temporada 1953-1954», IV, 78, p. 10.

«Comunicación personal sobre el Lope de Vega», IV, 79, p.10.

«Diez días al arte abstracto», IV, 79, p. 9.

«Otra vez la belleza», IV, 81, p. 10.

«La tragedia americana», IV, 82, p. 10.

«Jean Anouilh», IV, 83, p. 10.

«Teatro Popular», IV, 84, p. 10.

«Teología del drama», IV, 85, p. 10.

«Tragedia antigua y tragedia moderna», IV, 86, p. 10.

«Eugenio O'Neill en la resurrección de la tragedia», IV, 86, p. 12.

«Tercer teatro», V, 87, p. 10.

«Zalamea y su Alcalde», V, 88, p. 10.

«Cinco cartas de felicitación», V, 89, p. 10.

«La "katharsis" trágica», V, 90, p. 10.

«Enrique Jardiel Poncela», V, 91, p. 10.

«La tragedia y el tiempo», V, 92, p. 10.

«El teatro y el cine», V, 93, p. 10. 


\section{José María de Quinto}

«Ni teatro de ensayo ni teatro de cámara; sino todo lo contrario» II, 31, p. 5. «La tesis es la tisis del drama», II, 32, p. 12.

«Europa, América y sus dos teatros», III, 55, pp. 1, 8.

«El intimismo en la literatura social», III, 61, p. 3..

«Mucho ruido y pocas obras», IV, 70, p. 10.

«El actual teatro italiano en la escena española», IV, 75, p. 10

«La programación, tarea de verano», IV, 76, p. 14.

«Teatro al aire libre», IV, 77 , p. 10.

«Teatro lírico y teatro de ensayo», IV, 78, p. 10.

«Crónica de la quincena», IV, 81, p. 10.

«Crónica de la quincena», IV, 82, p. 10.

«Crónica de la quincena», IV, 83, p. 10.

«Crónica de la quincena», IV, 84, p. 10.

«Crónica de la quincena», IV, 85, p. 10.

«Crónica de la quincena», IV, 86, p. 10.

«Crónica de la quincena», IV, 87, p. 10.

«Crónica de la quincena», IV, 88, p. 10.

«Crónica de la quincena», IV, 89, p. 10.

«Crónica de la quincena», IV, 91, p. 10.

«Crónica de la quincena», IV, 92, p. 10.

«Crónica de la quincena», IV, 93, p. 10. 